\title{
ENDOGENOUS CUSHING'S SYNDROME: The Filipino Clinical Experience Of 19 Cases
}

Tom Edward Lo MD, Joyce Cabradilla MD, Sue Ann Lim MD and Cecilia Jimeno MD Philippine General Hospital- Department of Medicine- Section of Endocrinology and Metabolism

\section{BACKGROUND AND SIGNIFICANCE}

- Cushing's Syndrome $\rightarrow$ Excessive Steroid Level

- Exogenous steroid intake $\rightarrow$ Most common cause

- Endogenous causes of Cushing's Syndrome is rare with an incidence of approximately 13 cases per million population.

- In Asia, and specifically in the Philippines incidence is unknown.

- Clinical presentation among Filipinos is not well described.

- The local epidemiology of obesity, diabetes and hypertension are different from other countries.

- Due to its rarity, it is difficult to rapidly assess and diagnose such patients.

- This description and collection of cases adds to the clinical knowledge and provides Filipino physicians clues in recognizing possible cases for screening.

\section{METHODOLOGY}

Medical Records with Cushing's Syndrome $(2005-2011) \rightarrow$ ICD 10 (E24) and Endo Logbooks

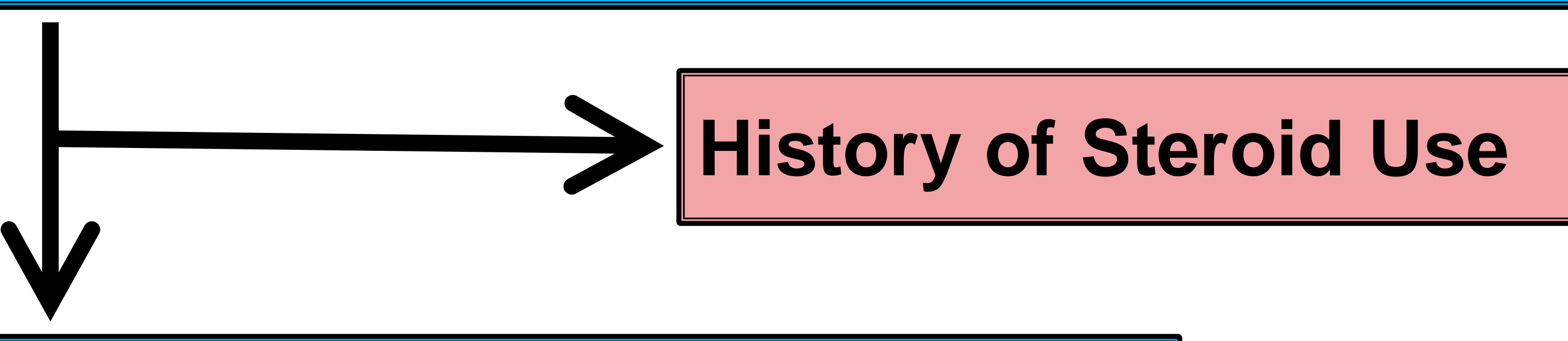

Endogenous Cushing's Syndrome<smiles>C1C[Al]1</smiles>

Documentation of Clinical and Biochemical Profiles, Radiologic workups and Outcomes

\section{RESULTS}

- $\mathrm{N}=19$ cases (8 pituitary adenoma, 7 adrenal adenoma, 4 ectopic adenoma)

- Female predominance was noted (Table 1).

- Weight Gain - Most common symptom

- Moon Facies - Most common sign

- Ectopic sources $\rightarrow$ Short clinical course, hyperpigmentation, ecchymoses, behavioural changes and severe hypokalemia

- All cases had significantly elevated midnight serum cortisol level and 24 hour urine cortisol with ectopic sources exhibiting the highest level (Figure 1).

- There was no observed correlation between the tumour size and level of serum cortisol in all types (Figure 2).

- Majority underwent tumour resection leading to complete reversal of steroid excess.
Table 1: Baseline Characteristics of Endogenous Cushing's Syndrome

\begin{tabular}{|l|c|c|c|c|}
\hline $\begin{array}{c}\text { Baseline } \\
\text { Characteristics }\end{array}$ & $\begin{array}{c}\text { Endogenous } \\
\text { Cushing's } \\
(\mathrm{n}=19)\end{array}$ & $\begin{array}{c}\text { Pituitary } \\
(\mathrm{n}=8)\end{array}$ & $\begin{array}{c}\text { Adrenal } \\
(\mathrm{n}=7)\end{array}$ & $\begin{array}{c}\text { Ectopic } \\
(\mathrm{n}=4)\end{array}$ \\
\hline Age & $30 \pm 10$ & $\begin{array}{c}24.6 \pm \\
2.3\end{array}$ & $\begin{array}{c}34.4 \pm \\
11.7\end{array}$ & $\begin{array}{c}31.5 \pm \\
14.5\end{array}$ \\
\hline $\begin{array}{l}\text { Female } \\
\text { Percentage }\end{array}$ & $89.5 \%$ & $87.5 \%$ & $100 \%$ & $75 \%$ \\
\hline $\begin{array}{l}\text { Disease } \\
\text { Duration (yr) }\end{array}$ & $2.3 \pm 3$ & $3.6 \pm 3.6$ & $1.6 \pm 2.4$ & $\begin{array}{c}0.83 \pm \\
0.81\end{array}$ \\
\hline Hypertension & $84.2 \%$ & $75 \%$ & $85.7 \%$ & $100 \%$ \\
\hline Diabetes & $26.3 \%$ & $25 \%$ & $28.6 \%$ & $25 \%$ \\
\hline Mortalities & $21.1 \%$ & $0 \%$ & $14.3 \%$ & $75 \%$ \\
\hline
\end{tabular}

Figure 1: Biochemical Features Among Different Sources of Endogenous Cushing's Syndrome

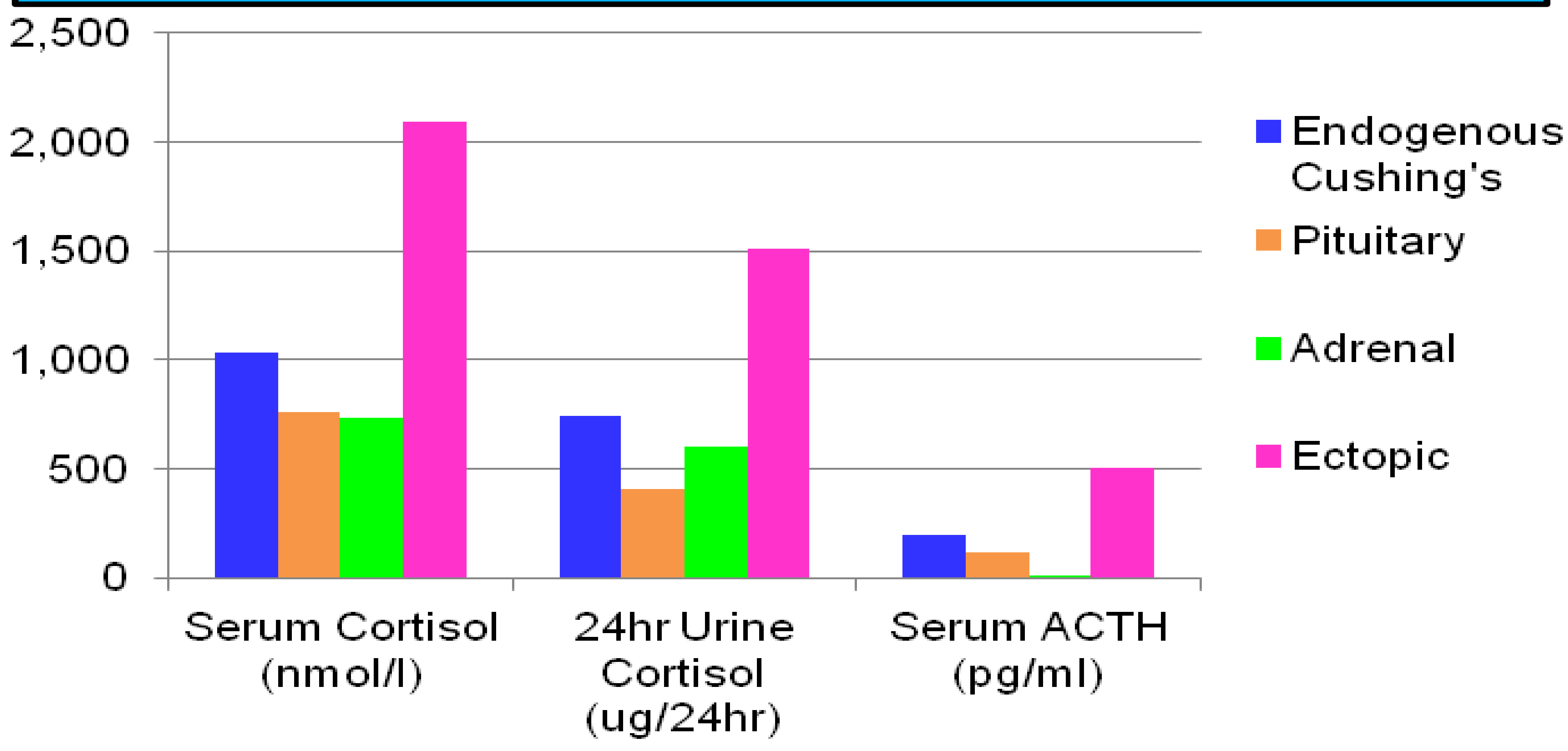

Figure 2: Correlation of Tumor Size and Serum Cortisol Among Different Sources of Endogenous Cushing's Syndrome

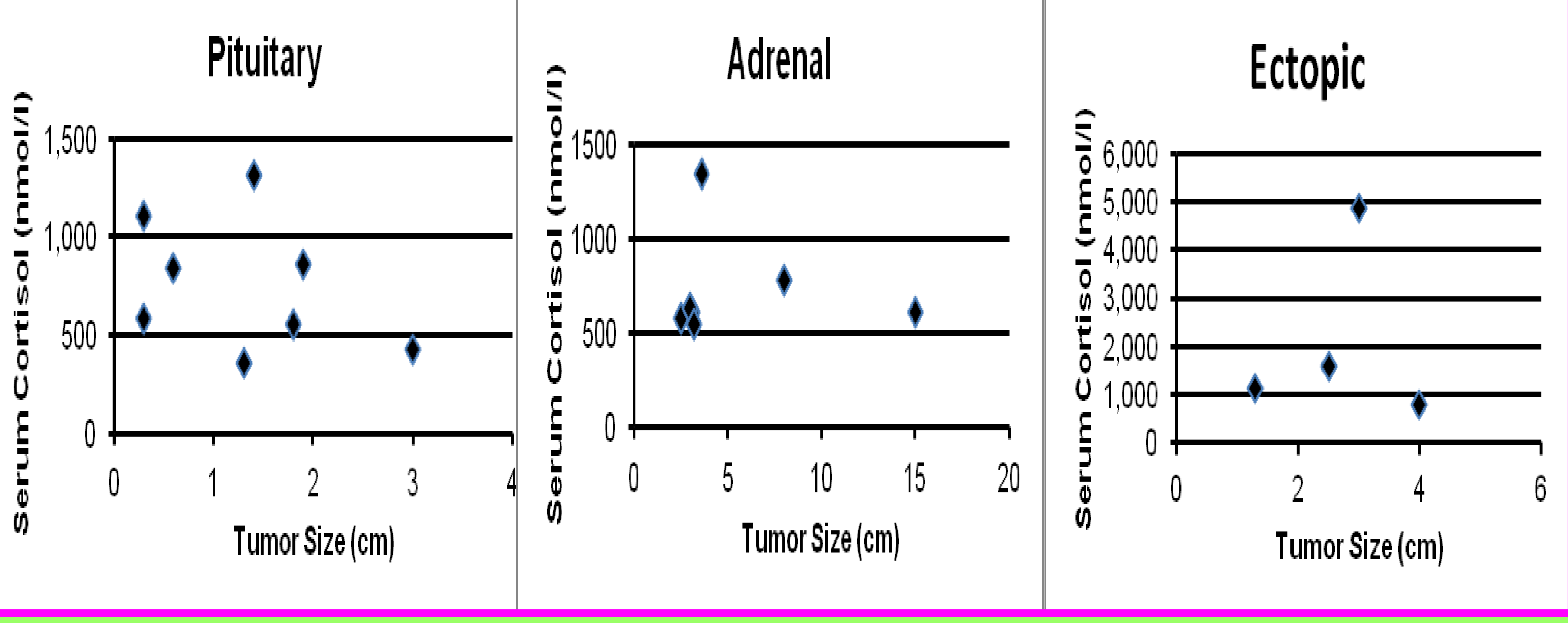

\section{CONCLUSION}

- Adrenal, pituitary and ectopic foci are the main sources of endogenous steroid excess.

- Ectopic ACTH syndrome manifests differently with other causes providing clues that might help in rapid clinical differentiation.

- Imaging studies should only be used to confirm tumour location after rigorous biochemical tests.

- Surgical management remains to be the definitive cure for most of the cases, hence prompt diagnosis and localization is necessary. 